\title{
Comparative Study of Ketamine and Fentanyl When Added to Intrathecal Bupivacaine on Sensory and Motor Blockade in Patients Undergoing Total Abdominal Hysterectomy
}

\author{
Saba Wani ${ }^{1}$, Sadia Ali Wani ${ }^{1}$, Salma Mariyam ${ }^{1}$, Saika ${ }^{2}$, Heena Chowdhary ${ }^{2}$, \\ Zaheer Ahmed ${ }^{3}$ \\ ${ }^{1}$ Department of Anaesthesia and Critical Care GMC Rajouri, Jammu and Kashmir, India. \\ ${ }^{2}$ Department of Obstetric and Gyaenecology GMC Rajouri, Jammu and Kashmir, India. \\ ${ }^{3}$ Department of Surgey GMC Rajouri, Jammu and Kashmir, India.
}

\begin{abstract}
Introduction:- Ketamine and Fentanyl used intrathecally as adjuvant to $0.5 \%$ hyperbaric bupivacaine for patients undergoing TAH to shorten the onset of sensory and motor blockade and prolonging the duration of block.

Aims and Objective:-We evaluated onset and duration of sensory and motor blockade and timing of regression of sensory blockade to $\mathrm{T} 12$ and motor blockade to Bromage scale 3.

Material and Methods:- This analytical Comparative Study was conducted in Department of Anaesthesiology, Era's Lucknow Medical College and Hospital, Era University, Lucknow over a period of eighteen months from $2016-2018$ following approval from institutional ethical committee and written informed patient consent. The sample size of 162 female patient aged 40 to 60 years, belonging to ASA physical status 1 and 2 undergoing TAH were randomly allocated to three groups in double blind manner. Group I Received Inj. Bupivacaine (0.5\% Heavy) $3.0 \mathrm{ml}$ + Inj. Ketamine (25 mg), Group II Received Inj. Bupivacaine $(0.5 \%$ Heavy) $3.0 \mathrm{ml}+$ Inj. Fentanyl $(25 \mu \mathrm{gm})$, Group III (Control Group): Received Inj. Bupivacaine (0.5\% Heavy) $3.0 \mathrm{ml}$ + Normal saline $0.5 \mathrm{ml}$. Onset and Duration of Sensory and Motor Blockade and time taken for regression of sensory level to T12 and motor level to Bromage scale 3 noted.
\end{abstract}

Results:- The present study showed that both Ketamine as well as Fentanyl shortened the onset time and prolonged the block duration. However, with respect to onset time, ketamine has shorter onset of blockade than fentanyl.

Conclusion:- Both the modalities independently assured quicker onset and prolonged duration of block, thus suggesting that adjuvant use of either of two could be beneficial.

Keywords: TAH, Ketamine, Fentanyl, Bupivacaine.

\section{INTRODUCTION}

Hysterectomy is one of the most common gynecologic operations performed in developed countries and is usually performed for Benign disorders such as Fibroids, Endometrial Hyperplasia, Adenomyosis, Endometriosis, Uterine prolapse, Dysfunctional Uterine Bleeding and Cervical Intraepithelial Neoplasia ${ }^{1,2,3}$.

Approximately one in three women has undergone a hysterectomy by age 60 , with approximately 600,000 hysterectomies performed annually in the United States ${ }^{4}$.

Earlier general anaesthesia was considered to be the standard anaesthetic technique for $\mathrm{TAH}$, although it provides effective intraoperative analgesia, muscle relaxation and unawareness yet it contributes to unfavourable postoperative symptoms such as PONV, fatigue and drowsiness. 
Hence in recent years, regional blocks such as spinal, epidural and a combination of spinal / epidural blocks with general anaesthesia have gained widespread popularity among the surgical fraternity and have been well accepted by both the patient as well as the surgeon.

Bupivacaine is the most commonly anaesthetic agent used for gynaecological surgeries, but the duration of spinal anaesthesia may be short and limited, and higher doses of rescue analgesics may be required in the postoperative period. This can be avoided by using higher doses of bupivacaine which again can produce cardiac toxicity ${ }^{5}$ while reducing the dose of bupivacaine used in spinal anaesthesia helps to achieve rapid anaesthetic recovery, but may result in anaesthetic failure 6 . Intrathecal adjuncts such as opioids ${ }^{7}$, vasoconstrictors ${ }^{8}, \alpha-2$ agonists ${ }^{9}$, and neostigmine ${ }^{10}$ are often added to enhance spinal anaesthesia.

Ketamine is an anaesthetic agent with potent analgesic properties used as an adjunct in spinal anaesthesia. It has a local anaesthetic effect and a non-competitive antagonistic effect on $\mathrm{N}$-methyl d-aspartate receptors ${ }^{11}$. Ketamine exerts analgesic effects after epidural, caudal, or intrathecal administration 12,13. Most commonly used opioid in regional anaesthesia is fentanyl citrate. It is a highly potent drug because of its high lipophilicity. It is preferred as an adjuvant in spinal anaesthesia because of its rapid onset and short duration of action with minimal cephalic spread ${ }^{14,15}$.

The present study was proposed to compare the adjuvant effect of Ketamine and Fentanyl among patients undergoing Total Abdominal hysterectomy.

\section{AIM AND OBJECTIVES}

AIM:-

To compare the effects of ketamine versus Fentanyl on quality of blockade when added to intrathecal Bupivacaine in spinal anesthesia for Total Abdominal Hysterectomy.

\section{OBJECTIVES:-}

The aim of the present study has following objectives

1. Observation of (a) Onset (defined as the time between injection and achievement of highest level of sensory blockade), (b) Duration of sensory and motor blockade, (c) Regression of sensory and motor blockade following administration of Ketamine and Fentanyl as adjuvants to intrathecal Bupivacaine in patients undergoing abdominal hysterectomy under spinal anesthesia.

\section{MATERIAL AND METHODS TYPE OF STUDY}

Analytical Comparative Study.

\section{PLACE OF STUDY}

Department of Anaesthesiology, Era's Lucknow Medical College and Hospital, Era University, Lucknow.

\section{DURATION OF STUDY}

Eighteen months.

\section{APPROVALS AND PERMISSIONS}

After obtaining clearance from the institutional ethical committee, 156 females aged 40-60 years of age, body weight 50-70 $\mathrm{kg}$, scheduled for abdominal hysterectomy were enrolled for the study. All the patients were informed regarding the procedure and about the anaesthetic agents used in the study, and were allowed to raise queries regarding the same. Consent of each patient was obtained before inclusion in the study

\section{SAMPLE SIZE}

Sample size was calculated by the Department of Social \& Preventive Medicine, Era's Lucknow Medical College using the formula based on variation in motor blockade in two groups using the following formula:

$$
\mathrm{n}=\frac{\left(\sigma_{1}^{2}+\sigma_{2}^{2}\right)(Z \alpha+Z \beta)^{2}}{d^{2}}
$$


The sample size comes out to be 52 for each group.

Total of 156 females were enrolled in the study, who were further randomly allocated into three Groups having 52 patients in each group.

Group I: Administered Inj. Bupivacaine $(0.5 \%$ Heavy) $3.0 \mathrm{ml}+$ Inj. Ketamine $(25$ $\mathrm{mg}$ ).

Group II: Administered Inj. Bupivacaine (0.5\% Heavy) $3.0 \mathrm{ml}+$ Inj. Fentanyl (25 $\mu \mathrm{gm})$

Group III (Control Group): Administered Inj. Bupivacaine $(0.5 \%$ Heavy $) 3.0 \mathrm{ml}+$ Normal saline $0.5 \mathrm{ml}$.

\section{INCLUSION CRITERIA}

1. Patient scheduled for abdominal hysterectomy.

2. ASA Grade-I \& II.

3. Age group of 40-60 years.

4. Body weight 50-70 kg.

\section{EXCLUSION CRITERIA}

1. ASA Grade III \& IV.

2. Patients refused to enrol for the study.

3. Patients with a history of respiratory, cardiac or hepatorenal disorder.

4. Patients with severe neurological deficit.

5. Patient with history of chronic alcoholism or drug abuse

6. Patients with bradycardia, hypertension.

7. Clotting and Bleeding disorder

8. Patients with allergy to drug used

\section{METHODOLOGY}

- Pre-anaesthetic check up was done.

- Informed consent for the anaesthesia and inclusion in the study were obtained.

- Patients were kept NPO over night.

- Intravenous cannulation was carried out with $18 \mathrm{G}$ cannula after shifting the patient in pre operative ward.

- After shifting the Patients to the operation theatre non- invasive blood pressure cuff (NIBP), pulse oximeter probe and electrocardiographic leads were attached.

- Baseline parameters were recorded.
- Preloading was carried out with an IV infusion of a litre of Ringers Lactate

- Under all aseptic precautions, 25G Quincke-Babcock Spinal needle was introduced in L3-L4 space.

- Following free flow of CSF the patients were administered Inj. Bupivacaine $0.5 \%$ Heavy $3.0 \mathrm{ml}$ along with test drug (Inj. Ketamine $25 \mathrm{mg} / \mathrm{Inj}$. Fentanyl 25 $\mu \mathrm{gm} /$ Normal saline $0.5 \mathrm{ml}$.)

- Sensory blockade was assessed using Cold sensation using spirit swabs in mid-axillary line bilaterally or Pinprick

- Motor block was assessed by using Modified Bromage score.

- The highest sensory block level and recovery time of both sensory and motor block was recorded.

- Time taken to reach Bromage scale 3 was calculated on onset of motor blockade

- Sensory and Motor blocks were assessed every 2 mins for fist $10 \mathrm{mins}$ and thereafter every 15 mins during surgery.

- Regression time to reach sensory level up to $\mathrm{T}_{12}$ was recorded.

The parameters recorded were:

- Heart Rate (HR).

- Systolic Blood Pressure (SBP).

- Diastolic Blood Pressure (DBP).

- Level of sensory block.

- Duration of sensory/motor block

The parameters are recorded at following time intervals (in min) T-0, T-2, T-4, T-6, T-8, T-10, T-25, T-40, T-55, T-70, T-85, T-100, T-115

\section{EQUIPMENTS REQUIRED}

- Anaesthesia Work Station.

- Multipara monitor.

- Resuscitatory equipments.

All the patients were examined clinically, hemodynamic parameters recorded during and before surgery were noted on a separate case record form for individual patient and thereafter entered on a Microsoft excel sheet for analysis. 


\section{Statistical Tools Employed}

The statistical analysis was done using SPSS (Statistical Package for Social Sciences) Version 21.0 statistical Analysis Software. The values were represented in Number $(\%)$ and Mean \pm SD.

\section{RESULTS}

The present study was conducted in the Department of Anaesthesiology, Era's Lucknow Medical College \& Hospital, Era
University, Lucknow to compare the effects of ketamine and fentanyl on motor and sensory blockade when added to intrathecal bupivacaine in spinal anaesthesia for abdominal hysterectomy. A total of 156 females scheduled for abdominal hysterectomy were enrolled in the study after obtaining an informed consent. These patients were divided in three groups as under:

Table 1: Distribution of Study Population

\begin{tabular}{|c|c|c|c|c|}
\hline SN & Group & Description & No. of patients & Percentage \\
\hline $1-$ & Group I & Inj. Bupivacaine 0.5\% Heavy 3.0ml + Inj. Ketamine $(25 \mathrm{mg})$ & 52 & 33.3 \\
\hline $2-$ & Group II & Inj. Bupivacaine 0.5\% Heavy 3.0ml + Inj. Fentanyl $(25 \mu \mathrm{gm})$ & 52 & 33.3 \\
\hline $3-$ & Group III & Inj. Bupivacaine 0.5\% Heavy 3.0ml + Normal saline 0.5 ml & 52 & 33.3 \\
\hline & & & 156 & 100.0 \\
\hline
\end{tabular}

Table 1: Intergroup Comparison of Duration of Block (minutes) of Study Population

\begin{tabular}{|c|c|c|c|c|c|}
\hline Group & No. of cases & Min. & Max. & Mean & S.D. \\
\hline Group I & 52 & 135.00 & 162.00 & 147.21 & 5.46 \\
\hline Group II & 52 & 149.00 & 178.00 & 163.87 & 6.02 \\
\hline Group III & 52 & 114.00 & 132.00 & 121.62 & 4.34 \\
\hline Total & 156 & 114.00 & 178.00 & 144.23 & 18.21 \\
\hline \multicolumn{6}{|c}{$F=832.019 ; p<0.001(N S)$}
\end{tabular}

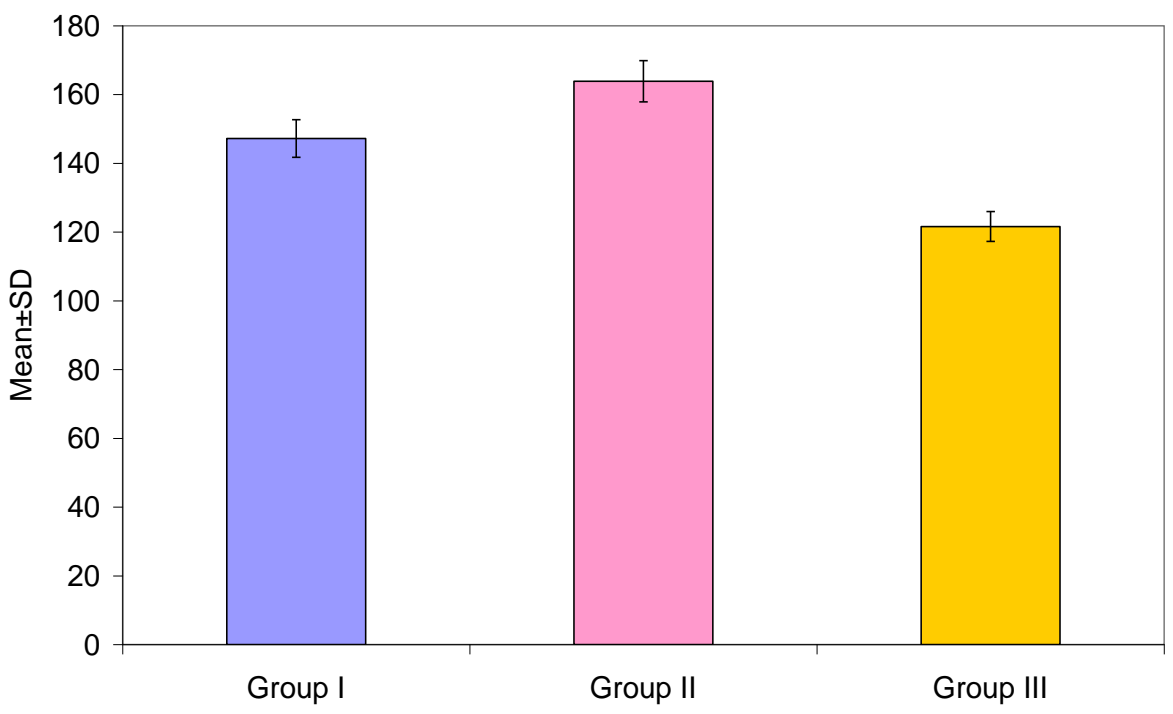

Fig. 1: Intergroup Comparison of Duration of Block (minutes) of Study Population

Duration of block of in patients of Group III was minimum $(121.62 \pm 4.34 \mathrm{~min})$ followed those in Group I (147.21 $\pm 5.46 \mathrm{~min})$ and maximum in Group II (163.87 $\pm 6.02 \mathrm{~min})$. On exploring the be Introduction:- Ketamine and Fentanyl used intrathecally as adjuvant to $0.5 \%$ hyperbaric bupivacaine for patients undergoing $\mathrm{TAH}$ to overcome the cardiac toxicity from higher dose of bupivacaine.

Between group differences Duration of block of Group II > Group I > Group III.

Table 2: Intergroup Comparison of time to achieve Sensory Block (T5) (minutes) of Study Population

\begin{tabular}{|c|c|c|c|c|c|}
\hline Group & No. of cases & Min. & Max. & Mean & S.D. \\
\hline Group I & 52 & 6 & 8 & 7.15 & 1.00 \\
\hline Group II & 52 & 6 & 10 & 8.69 & 1.31 \\
\hline Group III & 52 & 10 & 10 & 10.00 & 0.00 \\
\hline Total & 156 & 6 & 10 & 7.33 & 1.12 \\
\hline \multicolumn{6}{|c|}{$F=117.141 ; p<0.001$ (Sig) }
\end{tabular}


Saba Wani et.al. Comparative study of ketamine and fentanyl when added to intrathecal bupivacaine on sensory and motor blockade in patients undergoing total abdominal hysterectomy.

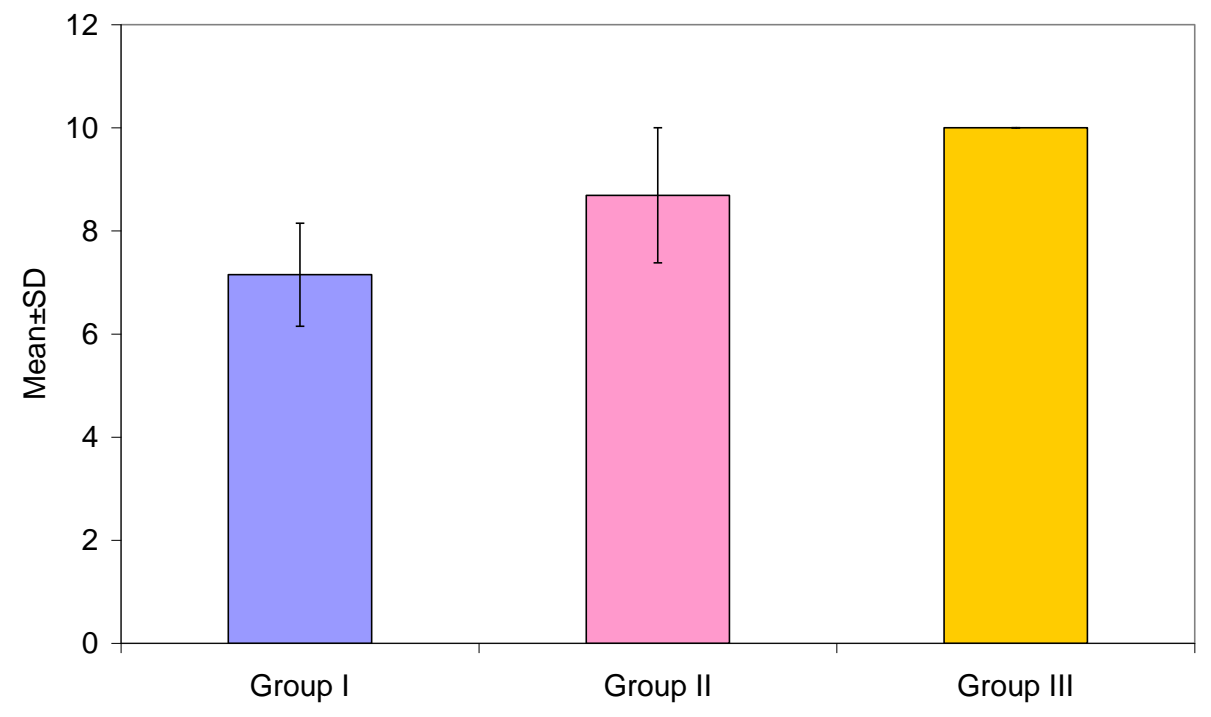

Fig. 2: Intergroup Comparison of time to achieve Sensory Block (T5) (minutes) of Study Population

Time to achieve sensory block among patients of Group I was earliest $(7.15 \pm 1.00$ $\mathrm{min}$ ) followed by those of Group II $(8.69 \pm 1.31 \mathrm{~min})$ and last in Group III (10.00 $\pm 0.00 \mathrm{~min})$. On exploring the between group differences Time to achieve sensory block upto level T5 was earliest in Group I followed by Group II and III respectively.

\begin{tabular}{l} 
Table3: Intergroup Comparison of time to achieve Motor Block (Bromage score 3) (minutes) of Study Population \\
$\qquad$\begin{tabular}{|c|c|c|c|c|c|}
\hline Group & No. of cases & Min. & Max. & Mean & S.D. \\
\hline Group I & 52 & 6.00 & 8.00 & 6.62 & 0.93 \\
\hline Group II & 52 & 4.00 & 8.00 & 7.15 & 1.07 \\
\hline Group III & 52 & 8.00 & 10.00 & 8.23 & 0.65 \\
\hline Total & 156 & 4.00 & 10.00 & 7.33 & 1.12 \\
\hline
\end{tabular} \\
\hline
\end{tabular}

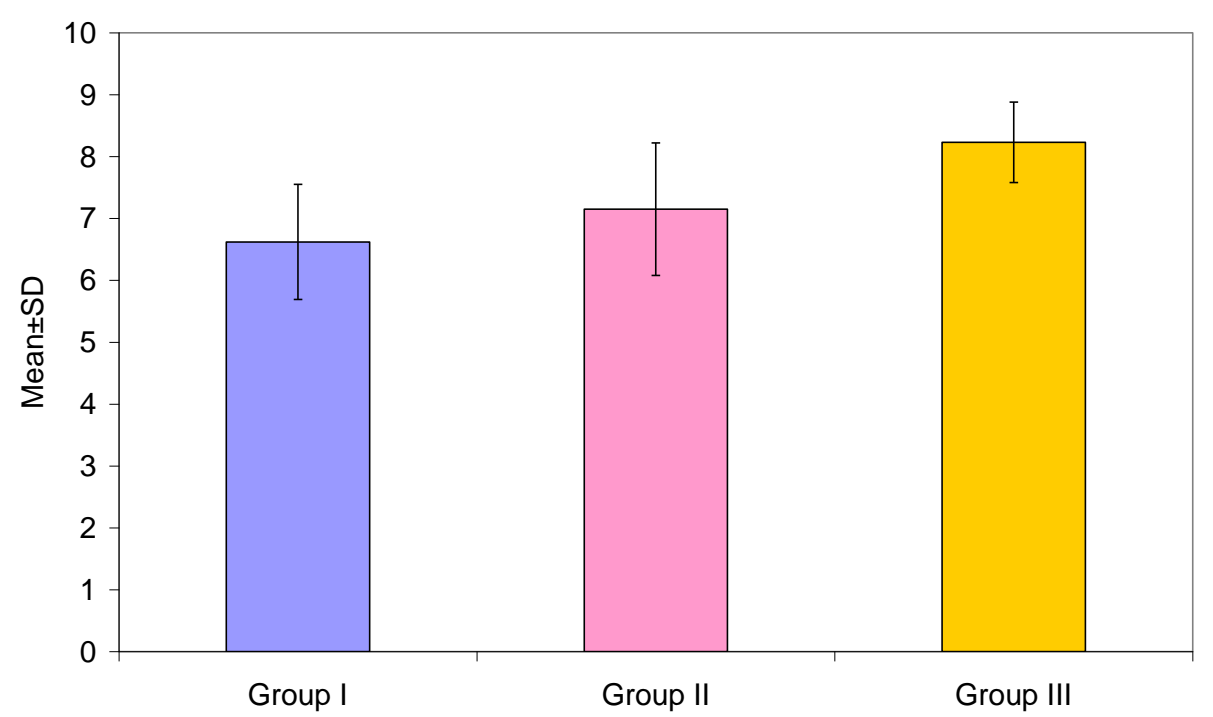

Fig. 3: Intergroup Comparison of time to achieve Motor Block (Bromage score 3) (minutes) of Study Population

Time to achieve motor block among patients of Group I was earliest (6.62 \pm 0.93 min) followed by those of Group II $(7.15 \pm 1.07 \mathrm{~min})$ and last in Group III $(8.23 \pm 0.65 \mathrm{~min})$. On exploring the between group differences Time to achieve motor block T5 Group I < Group II < Group III.

\section{DISCUSSION}

The present study, thus showed that both Ketamine as well as Fentanyl 
shortened the onset time and prolonged the block duration. However, with respect to onset time, ketamine performed better as compared to fentanyl but with respect to block duration, fentanyl outscored ketamine, as seen in previous study done by Shrestha et al and Unlugenc et al. A higher concentration of non-ionized bupivacaine could result in more rapid onset of action, since only this lipid-soluble form diffuses across the neural sheath and nerve membrane ${ }^{16}$. This property of the ketamine could increase the concentration of nonionized bupivacaine by providing more acidic environment, which results in extensive and rapid absorption from the subarachnoid space. However, Ahmed et al. while comparing the adjuvant use of ketamine and fentanyl for peribulbar block for vitroretinal surgeries did not find a significant difference in block duration as well as onset time of two groups, thus indicating that type of block and route of administration could have an impact on the performance of adjuvants.

In view of only few clinical studies comparing the two drugs, further studies with variable dosages of the two drugs are recommended to validate the findings of present study and to find the optimum drugdose combination.

\section{CONCLUSION}

The findings of present study thus suggested that from the point of view of clinical usefulness, fentanyl had an edge over ketamine in terms of statistically as well as clinically significant prolongation of block duration, however, if a quicker onset of block is the objective ketamine could be the preferred modality

\section{Acknowledgement: None}

\section{Conflict of Interest: None}

Source of Funding: None

Ethical Approval: Approved

\section{REFERENCES}

1. Whiteman MK, Hillis SD, Jamieson DJ, Morrow B, Podgornik MN, Brett KM, et al. Inpatient hysterectomy surveillance in the United States, 2000-2004. Am J Obstet Gynecol. 2008;198:34.e1-34.e7.

2. Wallwiener M, Taran FA, Rothmund R, Kasperkowiak A, Auwarter G, Ganz A, et al. Laparoscopic supracervical hysterectomy (LSH) versus total laparoscopic hysterectomy (TLH): an implementation study in 1,952 patients with an analysis of risk factors for conversion to laparotomy and complications, and of procedurespecific re-operations. Arch Gynecol Obstet. 2013;288:1329-39.

3. Ayoubi JM, Fanchin R, Monrozies X, Imbert P, Reme JM, Pons JC. Respective consequences of abdominal, vaginal, and laparoscopic hysterectomies on women's sexuality. Eur J Obstet Gynecol Reprod Biol. 2003;111:179-82.

4. Whiteman MK, Hillis SD, Jamieson DJ, Morrow B, Podgornik MN, Brett KM, et al. Inpatient hysterectomy surveillance in the United States, 2000-2004. Am J Obstet Gynecol. 2008;198:34.e1-34.e7.

5. Routray SS, Raut K, Pradhan A, Dash A, Soren M. Comparison of intrathecal clonidine and fentanyl as adjuvant to hyperbaric bupivacaine in subarachnoid block for lower limb orthopedic surgery. Anesth Essays Res 2017;11:589-93

6. Ben-David B, Solomon E, Levin H, Admoni $\mathrm{H}$, Goldik Z. Intrathecal fentanyl with small-dose dilute bupivacaine: better anesthesia without prolonging recovery. Anesth Analg 1997; 85:560-565.

7. Chaney MA. Side effects of intrathecal and epidural opioids. Can J Anaesth 1995; 42:891-903.

8. Sakura S, Sumi M, Sakaguchi Y, Saito Y, Kosaka Y, et al. The addition of phenylephrine contributes to the development of transient neurologic symptoms after spinal anesthesia with $0.5 \%$ tetracaine. Anesthesiology 1997; 87:771778.

9. Eisenach JC, De Kock M, Klimscha W. Alpha (2)-adrenergic agonists for regional anesthesia. A clinical review of clonidine (1984-1995). Anesthesiology 1996; 85:655674.

10. Liu SS, Hodgson PS, Moore JM, Trautman WJ, Burkhead DL. Dose-response effects of 
Saba Wani et.al. Comparative study of ketamine and fentanyl when added to intrathecal bupivacaine on sensory and motor blockade in patients undergoing total abdominal hysterectomy.

spinal neostigmine added to bupivacaine spinal anesthesia in volunteers. Anesthesiology 1999; 90:710-717.

11. Hirota K, Lambert DG. Ketamine: its mechanism(s) of action and unusual clinical uses. Br J Anaesth 1996; 77:441-444.

12. Hawksworth C, Serpell M. Intrathecal anesthesia with ketamine. Reg Anesth Pain Med 1998; 23:283-288.

13. Islas JA, Astorga J, Laredo M. Epidural ketamine for control of postoperative pain. Anesth Analg 1985; 64:1161-1162.

14. Singh H, Yang J, Thornton K, Giesecke $\mathrm{AH}$. Intrathecal fentanyl prolongs sensory bupivacaine spinal block. Can J Anaesth 1995;42:987-91.

15. Unal D, Ozdogan L, Ornek HD, Sonmez HK, Ayderen T, Arslan M, et al. Selective spinal anaesthesia with low-dose bupivacaine and bupivacaine fentanyl in ambulatory arthroscopic knee surgery. J Pak Med Assoc 2012;62:313-8.

16. Morgan GE, Mikhail MS, Murray MJ. Local anesthetics. Clinical Anesthesiology. The McGraw-Hill Companies, Inc, 2002: 233-240.

How to cite this article: Wani S, Wani SA, Mariyam S et.al. Comparative study of ketamine and fentanyl when added to intrathecal bupivacaine on sensory and motor blockade in patients undergoing total abdominal hysterectomy. International Journal of Research and Review. 2021; 8(8): 420-426. DOI: https://doi.org/10.52403/ijrr.20210858 